\title{
Inclusión social a través del arteterapia con enfoque de género, experiencias con migrantes latinoamericanas
}

\author{
Javiera HAUSER DACER ${ }^{1}$ \\ Universidad de Chile \\ javierahauser@gmail.com
}

Recibido: 21/11/12

Aceptado: 06/11/13

\begin{abstract}
RESUMEN
Las mujeres migrantes latinoamericanas juegan un papel significativo en las migraciones contemporáneas, integrándose al trabajo y a la cultura, contribuyendo así desarrollo, tanto de sus países de origen como de las sociedades de recepción.

La propuesta de trabajo corresponde a una intervención desde el arteterapia con enfoque de género realizada en el marco del Proyecto: "Servicio de apoyo psicológico, psicopedagógico y socioeducativo a colectivos con especiales dificultades de inserción social, educativa y laboral", financiado por el Fondo Social Europeo y gestionado por la Comunidad de Madrid y la Fundación Humanismo y Democracia.
\end{abstract}

Palabras clave: Arteterapia, inclusión social, mujeres migrantes, intervención social, enfoque de género.

\section{Referencia normalizada}

HAUSER DACER, J. (2013). "Inclusión social a través del arteterapia con enfoque de género, experiencias con migrantes latinoamericanas". En Arteterapia: Papeles de arteterapia y educación artística para la inclusión social Vol.: 8. Páginas 25-43.

\section{SUMARIO}

Mujeres Migrantes Latinoamericanas. Enfoque de Género. El Grupo de Arteterapia Corporal en el CEPI Hispano Colombiano de Villaverde. Reflexiones finales. Referencias bibliográficas.

\footnotetext{
${ }^{1}$ Doctora en Aplicaciones del Arte en la Integración Social: Arte, Terapia y Educación en la Diversidad y Máster en Estudios Interdisciplinares de Género por la Universidad Autónoma de Madrid. Postgrado en Arte Terapia, Universidad de Chile. Licenciada en Educación, Psicopedagoga, UMCE, Chile. Diploma en Técnicas Expresivas, Corporales y Grupales, Escuela de Terapia Corporal. Docente Postgrado en Terapias de Arte, mención Arte Terapia de la Universidad de Chile y actual Presidenta de la ACAT, Asociación Chilena de Arte Terapia. http://arteterapiaygenero.com/
} 


\title{
Social inclusion through art therapy with a focus on gender, experience with Latin American migrants
}

\begin{abstract}
Latin America migrant women are playing a significant role in contemporary migration movements, being integrated on their own jobs and new culture, thus helping development of both countries: origin and host societies.

The proposed work is an art therapy intervention from a gender perspective carried out under the project: "Service of psychological support, psycho-pedagogical and educational for groups with special difficulties of social insertion, educational and employment", funded by the European Social Fund and managed by the Community of Madrid and the Foundation Humanism and Democracy.
\end{abstract}

Keywords: Art Therapy, Social Inclusion, Immigrant Women, Social Intervention, Gender perspective.

\section{CONTENTS}

Latin American women migrants. Gender perspective. Body Art Therapy Group in Colombian Spanish CEPI Villaverde. Conclusions. References.

\section{MUJERES MIGRANTES LATINOAMERICANAS}

Es complejo esbozar las razones por las que en la actualidad las mujeres deciden emigrar. Se pueden deducir motivos tan diversos como lo han sido en otros momentos de la historia y en los que forman parte esencial elementos económicos, personales, demográficos, políticos y culturales, tanto de las sociedades de origen como de destino, que intervienen de manera distinta para mujeres y hombres. Huyen de guerras o persecuciones políticas, se trasladan para buscar alternativas económicas y libertad personal. Emigran equipadas con calificaciones personales y profesionales o con la urgencia de mantenerse a sí mismas y a sus familias. Se insertan en diferentes estratos ocupacionales, mantienen el contacto con sus lugares de origen, envían remesas, se quedan o vuelven a sus países de origen (Staab, 2003: 9).

En el caso específico de las mujeres migrantes latinoamericanas una de las principales, y más determinantes, causas de la migración son las condiciones de vida en los países de origen. A ello van unidas unas condiciones de trabajo muy precarias, como son: altos índices de empleo irregular, malas condiciones de trabajo, bajos salarios, etc. Son algunas de las características del mercado laboral de los países en Latinoamérica. Otro de los factores que impulsan la emigración es la presión demográfica en un contexto de escasos recursos, lo que se presenta con altas tasas de fecundidad. Por estas razones y otras condiciones, las mujeres que llegan a España son una población que percibe la escasez de oportunidades en sus países de origen y ve la migración como una estrategia hacia la búsqueda de prosperidad para ellas y sus familias. 
Los motivos vinculados a la necesidad de garantizar los ingresos económicos, siguen siendo uno de los primeros elementos a considerar a la hora de tomar la decisión de emigrar. Además, hoy en día, estos motivos económicos hay que contextualizarlos dentro de las desigualdades a nivel mundial. Se trata por tanto y en general, de una emigración económica en búsqueda de oportunidades laborales y de una vida mejor. "Algo, por cierto, muy parecido a lo que millones de españolas y españoles experimentaron hace no tantos años y que les llevó a emigrar, primero a América y luego a Europa" (Sallé, 2009:36). De acuerdo al diario electrónico el Confidencial, desde el año 2008 esta situación está volviendo debido a la crisis y los datos nos hablan de un $22 \%$ de emigración española, en su mayoría jóvenes, fundamentalmente en Alemania, Gran Bretaña e Iberoamérica. Otros de los destinos está siendo Noruega como bien lo refleja Carmen Pérez - Lanzac (2012), en su crónica del diario El País, "Atrapados en el norte",

\begin{abstract}
Noruega, con su petróleo, su (hoy más que nunca) envidiable Estado del bienestar, sus políticas de conciliación y, sobre todo, con sus elevados salarios y bajísimo desempleo ( $3 \%$ de tasa de paro), ha visto llegar en los últimos meses un nuevo perfil de emigrante que ha abandonado España empujado por el paro prolongado y por la progresiva merma de los salarios. Los periódicos noruegos los han bautizado "los refugiados laborales del euro".
\end{abstract}

Con estas circunstancias en los países de origen, otra de las variables que impulsa la decisión de emigrar de las mujeres latinoamericanas es la existencia de compatriotas, familiares, amigas/os en el país de acogida. Por otra parte, refiriéndose a un estudio realizado sobre "Las redes sociales de los inmigrantes extranjeros en España”, Sallé (2009) comenta que los contactos que mantienen las y los inmigrantes con sus parientes y amistades aquí residentes, antes de venir a España, influyeron en una tercera parte de los casos en los que estas personas emigraron. "Esta inmigración, basada en cadenas familiares y de paisanaje es muy común, sobre todo, entre la población procedente de Latinoamérica y de China. Son precisamente los hermanos y hermanas quienes más tiran de estas cadenas" (Zontini, 2005: 105).

De igual forma, su elevado papel como jefas de hogar, es decir, únicas responsables del bienestar familiar y propio, parece constituirse también como un factor clave en la decisión de emigrar. Estas mujeres cuentan con redes familiares fuertes que les va a permitir emigrar a ellas solas, dejando a sus hijas o hijos con sus familias. Algunas, como ya se ha señalado, pueden venir después de algún 
familiar que ha llegado primero o alguna amistad, sin embargo, en la mayoría de los casos entran como turistas y se quedan de forma irregular ${ }^{2}$.

El no contar con una documentación es para las mujeres migrantes una causa que aumenta su vulnerabilidad, porque padecen con mayor continuidad riesgos sociales tales como la pobreza, el desempleo y la subordinación. Poseen menos capacidad de respuesta individual e institucional para enfrentarlos y cuentan con un estigma en virtud del cual se las considera como dispuestas a ser tratadas o traficadas para cualquier actividad, debido a la falta de opciones en su país natal. Así, "la confluencia del género, etnia, nacionalidad e indocumentación puede conducir a las más extremas violaciones de derechos humanos, incluyendo abusos sexuales, deterioro de la salud reproductiva y amenaza a la integridad física" (Martínez, R.P., 2009: 8).

Uno de los principales objetivos de las mujeres, al venir a España, suele ser ganar dinero para mandarlo a sus familias en los países de origen. En consecuencia, encontrar un trabajo a la brevedad posible se convierte en una urgencia de primera necesidad para la mujer. Su situación, como se ha mencionado, es de vulnerabilidad. Mayoritariamente el trabajo que van a encontrar es en el servicio doméstico como "interna". Esto significa que vive en la misma casa que trabaja, y por tanto dependerá, del carácter altruista o explotador de la persona que la emplea. Pajares (2005) plantea que si toda la población inmigrante realiza los trabajos de menor nivel y remuneración, dentro de ese mismo grupo, son las mujeres las que ocupan la última clasificación: el servicio doméstico. En España, como en sus países de origen su trabajo se juzga como menos importante. Además aquí existe el prejuicio de qué solamente sirven para realizar ese tipo de trabajo y no se tienen en consideración ni su nivel de estudios ni su experiencia profesional en otros trabajos.

Las mujeres que logran regularizar su situación en España, tienen dificultades para encontrar un trabajo acorde a sus niveles de estudio - en el caso de que lo tenga- y cuando consiguen un empleo es por debajo de sus cualificaciones en actividades que no todas las personas están dispuestas a realizar, y muchas a su pesar deben seguir en el servicio doméstico. Las condiciones laborales siempre son inferiores a las mujeres españolas, siendo esta una de las razones por las que las contratan.

Es importante señalar las migraciones que emprenden mujeres jóvenes, provistas de un proyecto personal autónomo con una proyección emancipadora. Además, existe el lado opuesto que corresponde a las mujeres que vienen a España para trabajar en la prostitución. En este caso hay que tener en cuenta que muchas de ellas vienen a través de organizaciones de Trata y Tráfico de perso-

\footnotetext{
${ }^{2}$ Véase más información en la actual Ley Orgánica 2/2009, sobre derechos y libertades de los extranjeros en España y su integración social.
} 
$\operatorname{nas}^{3}$, lo que implica dedicarse a esta labor de forma involuntaria. Como podemos observar la cadena de motivaciones y de expectativas es muy diversa dentro de lo que implica un proyecto migratorio para estas mujeres.

Podemos afirmar, en líneas generales, que gran parte de las mujeres migrantes de hoy son producto de la "feminización de la pobreza". Ellas en sus países de origen suelen vivir en condiciones de dependencia o corresponsabilidad económica con el marido o la pareja. Eso en los casos que no forman parte de núcleos familiares mono parentales y responsables del cuidado familiar. Al llegar España esa situación cambia y pasan a ser proveedoras económicas y, en muchos casos, jefas de hogar con un proyecto propio. Algunas de ellas delegalan las tareas del cuidado de sus hijas e hijos a sus madres u otros miembros de la familia como ya se ha mencionado. Sin embargo, hay otras que intentan compatibilizar ambos roles como pueden. Estos cambios en sus vidas implican nuevas formas a la hora de enfrentar la existencia y subsistencia aún se desconoce bastante de este fenómeno que implica consecuencias en ambas sociedades, la de origen y la de acogida.

Al mismo tiempo, la migración femenina puede traer consigo, cuando quienes se marchan tienen hijas o hijos a su cargo, procesos de desestructuración familiar. En este sentido las nuevas tecnologías de información y comunicación podrían desempeñar un papel activo a la hora de propiciar la cercanía afectiva y el acompañamiento cotidiano entre las migrantes y sus redes familiares. No obstante, la realidad es otra, muchas mujeres acceden con dificultad a este tipo de tecnología

\footnotetext{
${ }^{3}$ Los términos "trata de seres humanos" y "tráfico de migrantes" han sido usados como sinónimos pero se refieren a conceptos diferentes. El objetivo de la trata es la explotación de las personas, en cambio el fin del tráfico es la entrada ilegal de migrantes. En el caso de la trata no es indispensable que las víctimas crucen las fronteras para que se configure el hecho delictivo, mientras que éste es un elemento necesario para la comisión del tráfico. La trata consiste en utilizar en provecho propio y de modo abusivo, las cualidades de una persona. Se utiliza la amenaza, el uso de la fuerza $u$ otras formas de coacción, el rapto, el fraude, engaño, abuso de poder o de una situación de vulnerabilidad. Además se considera trata de personas la concesión o recepción de pagos o beneficios para obtener el consentimiento de una persona que tenga autoridad sobre otra, con fines de explotación. La explotación incluirá, como mínimo, la explotación de la prostitución ajena u otras formas de explotación sexual, los trabajos o servicios forzados, la esclavitud o las prácticas análogas, la servidumbre o la extracción de órganos. El tráfico ha sido definido como la facilitación de la entrada ilegal de una persona en un Estado del cual dicha persona no sea nacional $o$ residente permanente con el fin de obtener, directa o indirectamente, un beneficio financiero $u$ otro beneficio de orden material. Las víctimas de trata y las personas objeto de tráfico, sean o no solicitantes de asilo, que se ven obligadas a ponerse a merced de las redes criminales internacionales, se encuentran en una situación de gran vulnerabilidad y expuestas a todo tipo de vejámenes y maltratos. La trata y el tráfico de personas son delitos que se han incrementado en forma alarmante en los últimos años, debido a las difíciles condiciones de vida en los países menos desarrollados, al endurecimiento de las políticas migratorias en los países industrializados y al hecho de que por mucho tiempo estos fenómenos no fueron considerados como un problema estructural sino como una serie de episodios aislados. Tomado de ACNUR. La agencia de la ONU para el Refugiado. Trata y Tráfico de personas.
} 
por una falta de conocimientos. De igual modo, se da el caso que algunas mujeres prefieren no destinar un dinero sea diario o semanal con este fin, lo consideran un gasto excesivo. De esta manera, se continúa generando en ellas un sentimiento de culpa y vulnerabilidad emocional.

Otras situaciones que se observan en muchas mujeres inmigrantes, son las dificultades para lograr la reagrupación familiar, o la falta de coberturas para atender a sus familias cuando se encuentran en con ellas. Respecto a la reagrupación de sus familias, esta se ha dificultado para las personas inmigrantes en general, luego que el Parlamento español aprobara en octubre del año 2009 la reforma de la Ley de Extranjería. Con ella ha quedado limitada la reagrupación a hijas o hijos menores de dieciocho años o mayores con discapacidad, así como, las madres y los padres de quien reagrupe y un eventual cónyuge, mayores de sesenta y cinco años. Aquí podemos observar como las políticas de reagrupación familiar pierden de vista el nuevo papel de las mujeres como cabezas de las cadenas migratorias y, por tanto, como protagonistas activas de los procesos de reagrupación, algo que debería suponer una flexibilización y agilización de los requisitos en estos casos.

Volviendo al tema de la irregularidad legal y laboral que, todavía hoy, soportan muchas mujeres inmigrantes puesto que no sólo es un problema en sí mismo sino que, además agrava las desigualdades de género. Una mujer sin papeles está mucho más expuesta a situaciones de exclusión social, violencia, abusos y violación sistemática de sus derechos, ya que el conjunto género - irregularidad- se potencia mutuamente como una cualidad que intensifica las desigualdades, aumentando así sus efectos hasta alcanzar niveles verdaderamente dramáticos.

Las políticas que adoptan los Estados en materia migratoria contienen las desigualdades que caracterizan al sistema de género vigente en la sociedad. Se basan todavía en una visión androcéntrica, en que se concibe al hombre como migrante activo y a la mujer como su dependiente (Cortés, 2005; Staab, 2003). Lim y Martínez, J. (2003 y 2006) coinciden con este diagnóstico al afirmar que, en general, las políticas de migración no son neutrales ante hombres y mujeres, lo que se traduce en una desigualdad de oportunidades, puesto que del estatus que adquiera la persona migrante al ingresar a un país determinado dependerán en gran medida las posibilidades de trabajo y de acceso a los servicios, entre otros factores. Además, aunque las políticas migratorias fueran neutrales ante el género, sus efectos o resultados podrían no serlo. En este escenario, además de una mirada de género, es indispensable utilizar un enfoque basado en los derechos humanos (Cortés, 2005).

\section{ENFOQUE DE GÉNERO}

Cuando Simone de Beauvoir declaró en 1949 que "una mujer no nace sino se hace”, su reflexión introdujo la investigación feminista que iba a desarrollarse a partir de los años setenta y ochenta. La filósofa francesa en su libro El segundo 
sexo respalda que las particularidades humanas pensadas como "femeninas" no proceden de una supuesta naturaleza biológica, sino que son adquiridas mediante un complejo proceso individual y social. Posteriormente las académicas feministas anglosajonas, en los años setenta, sistematizaron la propuesta de Beauvoir y la especificaron en el concepto género, que comenzó a utilizarse para referirse a la construcción sociocultural de los comportamientos, actitudes y sentimientos de mujeres y hombres. Sin embargo, es conveniente aclarar que en la actualidad no existe una sola definición de género y su definición vendrá dada por el lenguaje de una ciencia o bien por la elaboración teórica con la que se esté construyendo el conocimiento. Para el área en la que estamos situándonos utilizaremos la definición propuesta por Lourdes Benería:

El concepto de género puede definirse como el conjunto de creencias, rasgos personales, actitudes sentimientos, valores, conductas y actividades que diferencian a hombres y mujeres a través de un proceso de construcción social que tiene varias características. En primer lugar, es un proceso histórico que se desarrolla a diferentes niveles tales como el estado, el mercado de trabajo, las escuelas, los medios de comunicación, la ley, la familia y a través de las relaciones interpersonales. En segundo lugar este proceso supone la jerarquización de estos rasgos y actividades del tal modo que a los que se definen como masculinos se les atribuye mayor valor (1987:46).

Así definido, el género conduce a distintas interrogantes, entre los que cabe destacar: ¿cómo se forma dicha identidad? La respuesta a esta pregunta ha centrado los análisis del feminismo postmoderno, el cual rechazando la existencia de una identidad distintiva de cada unos de los sexos, como plantea el feminismo radical $^{4}$, enfatiza la pluralidad de identidades en un único sujeto, insistiendo en las diferencias que singularizan a mujeres y hombres. Fracturando, en tal sentido, el cartesiano sujeto humano unitario y sustituyendo el "ser" del pensamiento racionalista ilustrado por múltiples identidades subjetivas, nociones de diferencia, pluralidad y multiplicidad, los feminismos posmodernos nos afirman que "las mujeres son muchas y no una", acercándose al examen de la compleja e histórica interrelación entre el sexo, la clase, la etnia o la raza, de la inestable identidad

4 El feminismo radical hace de la "mujer" y de "hombre" dos categorías analíticas, en las que todas las personas de un mismo sexo conforman un grupo homogéneo identificable. Aunque ambas categorías eluden, por lo tanto, las diferencias entre personas del mismo sexo, se le ha criticado que su construcción se fundamenta sobre todo en la mujer occidental, blanca, de clase media y heterosexual. Véase: Harding, S. (1996), Ciencia y Feminismo. Madrid, Morata (traducción al castellano de la $5^{\text {a }}$ edición en inglés: The Science Question in Feminsm. Ithaca, Cornell University Press), 24. 
femenina, de la activa creación y recreación de los intereses y necesidades de las mujeres.

Cuando nos acercamos al género como construcción social, como una relación social que, penetrando en y constituyendo parcialmente, el resto de las relaciones sociales, nos muestra las condiciones reales las representaciones particulares de las relaciones entre la mujer y el hombre, los papeles que les han sido adjudicados socialmente o lo que significa ser mujer y ser hombre. Así pues este nivel de análisis nos remite a una expresión fundamental de las diferencias sociales, expresión vinculada, por lo demás, a la cultura, la raza o la clase, cuestiones estas que afectan de maneras en que el género es entendido. Pero el género es, además una categoría analítica construida a través de las relaciones sociales que nos ayudan a dar sentido a historias y mundos particulares, pues sólo mediante ellas sabemos lo que es y cómo se expresan.

A pesar de los actuales avances, alcanzados en políticas de igualdad de género a la mujer, se continúa intentando relegar al ámbito privado. Para abordar esta situación, las mujeres necesitan de espacios para reflexionar, opinar, crear y compartir sobre su experiencia y la de otras mujeres.

Atender a la dimensión personal de la mujer es un tema central de la innovación del feminismo en la actualidad. Las experiencias vividas en condiciones patriarcales $^{5}$ dañan a las mujeres y eso requiere atención. No bastan las acciones educativas, económicas, políticas, sociales, culturales y tecnológicas, es necesario intervenir específicamente.

Desde el paradigma feminista, lo primordial es el desarrollo de cada mujer concebido como la construcción de los derechos humanos de las mujeres en la vida propia. Implica continuar la más radical de las revoluciones históricas: la transformación compleja de la sociedad y la cultura para construir la convivencia de mujeres y hombres sin supremacía y sin opresión (Lagarde, 2000:18).

\section{EL GRUPO DE ARTETERAPIA CORPORAL EN EL CEPI ${ }^{6}$ HISPANO COLOMBIANO DE VILLAVERDE}

La propuesta de trabajo corresponde a una intervención desde el arteterapia corporal con enfoque de género realizada en el marco del Proyecto: "Servicio de

\footnotetext{
${ }^{5}$ Patriarcado entendido como un "sistema de organización social en el que los puestos claves de poder - político, económico, religioso y militar - se encuentran, exclusiva o mayoritariamente, en manos de varones". Véase más información en el libro Apuntes sobre violencia de género de Raquel Osborne (2009).

${ }^{6}$ Centros de Participación e Integración de la Comunidad de Madrid.
} 
apoyo psicológico, psicopedagógico y socioeducativo a colectivos con especiales dificultades de inserción social, educativa y laboral", la intervención se realiza en el CEPI Hispano Colombiano de Villaverde; una de las principales funciones del centro es la promoción de espacios para la participación y la integración.

El distrito de Villaverde está conformado por población de origen español y migrantes. La mujer española durante las últimas décadas se ha ido incorporando al empleo fuera del hogar, manteniendo a su vez el trabajo dentro de este, saliendo del espacio privado al espacio público. Esta situación provoca con el paso del tiempo y las actuales condiciones de la vida moderna, que las mujeres se sientan estresadas, insatisfechas a nivel personal, presenten sentimientos de melancolía, frustración, baja estimación personal, entre otros.

La mujer migrante, en el caso del distrito de Villaverde provienen de República Dominicana, Ecuador, Bolivia y Perú, se encuentran en unas determinadas circunstancias que se pueden calificar de fragilidad o vulnerabilidad, pueden ser víctimas de diversos delitos, pero con la particularidad de las dificultades añadidas a su proceso migratorio respecto al hombre migrante y situándola frente a las mujeres autóctonas en una situación de desventaja. Más patente si cabe, respecto a las mujeres en situación irregular, cuando quieren hacer valer sus derechos y acceder a todos los recursos disponibles para su protección, lo que se traduce en aislamiento, soledad, baja autoestima, incomunicación y falta de inclusión social.

La eliminación de obstáculos que impiden la igualdad real entre hombres y mujeres es parte de los objetivos que plantea el proyecto. Por lo tanto, se necesario ofrecer a las mujeres migrantes espacios para su desarrollo personal y social por medio de la intervención, sensibilización y formación, en relación a las temáticas que les afectan desde un enfoque de género.

\section{Descripción del grupo}

Se fundamenta en una de las Terapias Creativas, el Arteterapia disciplina dentro de las psicoterapias que se practica siguiendo unas metodologías específicas e innovadoras, con sus teorías y técnicas; utiliza el proceso creador y la obra u objeto artístico que se realiza bajo un marco o setting definido. Esta psicoterapia no se centra en el valor estético del trabajo artístico, sino sobre el proceso creativo. Considera, que toda persona, tenga o no formación artística, posee la capacidad para proyectar su creatividad por medio del arte. Las imágenes que se desarrollan en las sesiones son un nexo entre quienes las crean, la o el arteterapeuta y las temáticas que se reflexionan.

En la actualidad existen diversas definiciones acerca de qué es el arteterapia para este artículo señalaremos en primer lugar la que nos entrega una reconocida arteterapeuta de Tessa Dalley (1987:14) quien dice "el arteterapia se considera como el uso del arte en un contexto terapéutico, siendo lo más importante la persona y el proceso, donde el arte se utilizaría como un medio de comunicación no verbal". Siguiendo con sus planteamientos realiza una distinción entre arte, terapia y arteterapia para así comprender mejor el término. Postula que en el arte 
lo estético tiene una importancia primordial y que el producto final es un fin en sí mismo. La terapia por su parte, implica el propósito de provocar un cambio ante un desequilibrio humano. La actividad artística que se lleva a cabo en un entorno terapéutico, con propósitos de tratamiento y en presencia de un/a terapeuta, tiene unos objetivos y metas diferentes. La esencia reside en el resultado terapéutico de la actividad y el proceso de crear algo. La actividad artística proporciona un medio concreto, no verbal, a través del cual una persona puede lograr una expresión al mismo tiempo consciente e inconsciente y que puede emplearse como valioso agente de cambio terapéutico (Dalley, 1987).

Otra reconocida arteterapeuta Cathy Malchiodi (2010) considera que hay dos grandes categorías para definir lo que es el arteterapia, la primera implica una creencia en el poder curativo inherente al proceso creativo de hacer arte. Este punto de vista comprende la idea de que el proceso de hacer arte es terapéutico. Hacer arte es visto como una oportunidad para expresarse con imaginación, con autenticidad, y de forma espontánea, una experiencia que con el tiempo, puede conducir a la realización personal, la reparación emocional, y la transformación. La segunda definición se basa en la idea de que el arte es un medio de comunicación simbólica. Este enfoque a menudo denominado como la psicoterapia de arte, hace hincapié en los productos, dibujos, pinturas, y otras expresiones de arte, siendo útil en la comunicación de temas, emociones y conflictos. La imagen de arte se convierte en significado para aumentar el intercambio verbal entre la persona, la o el arteterapeuta y el logro de su significación en la solución de un conflicto o la formulación de nuevas percepciones que a su vez dan lugar a cambios positivos, el crecimiento personal y la curación.

Igualmente, el arteterapia es una herramienta para que las personas logren construir o reconstruir su identidad y pertenencia social, quedando de manifiesto el efecto sanador y la capacidad expresiva del arte.

En arteterapia, según Naumburg, no se trata tanto de que el arteterapeuta interprete las obras de sus pacientes, sino de que los anime a descubrirlas y a "leerlas" mediante la libre asociación e aspectos y mecanismos de su vida afectiva. De esta manera promueve la autonomía del paciente para que se independice cada vez más del terapeuta (Marxen, 2011:34-35). 


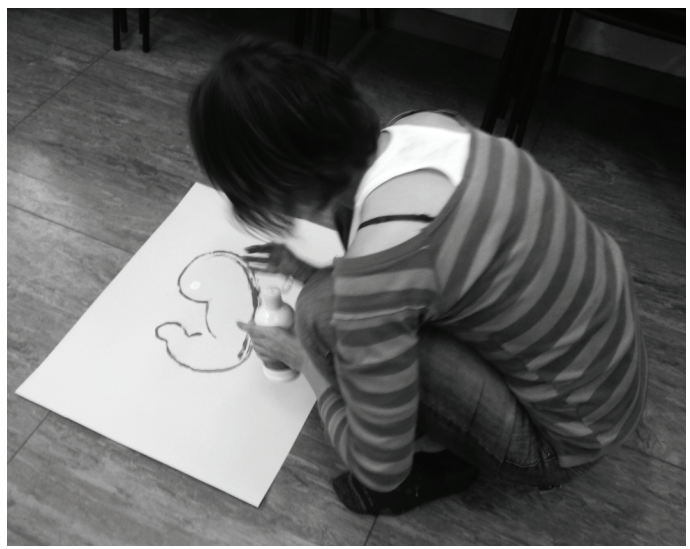

Fig. 1. Proceso creativo.

Otro de sus fundamentos del grupo es la Terapia Corporal, donde con cada movimiento una mujer u hombre va aumentando su potencial creativo. En cada una de las personas dicen Samuels y Rockwood (2000) hay un/a bailarín/a que puede crear una espiral curativa en torno a su Ser. Si nos sentimos suficientemente entregadas/os en el movimiento corporal podemos abrir un espacio interior hacia la realización de movimientos curativos.

La persona tiene la capacidad latente para expresarse corporalmente desde un espacio a otro, sí está en la mitad de las tareas laborales, sociales, personales o familiares, o sí mientras las hace cierra los ojos podrá ver que vive el movimiento de su propia vida. En vez de ir andando de un lugar a otro, la terapia corporal permite a la persona cambiar la perspectiva de su cuerpo. Se volverá decidida/o con su propia existencia, con sus habilidades y potencialidades, gracias a un acto deliberado y consciente.

Por otra parte, el grupo ha sido diseñado desde el Enfoque de Género que tiene en cuenta las desiguales oportunidades y trato que poseen las mujeres y los hombres, las correspondencias existentes entre ambos y los diferentes roles que socialmente se les establecen. Todos estos argumentos intervienen en el logro de las metas personales, la ciudadanía y participación, el empleo, la maternidad y por lo tanto, repercuten en el proceso de vida de las mujeres y el desarrollo de la sociedad.

La autotransformación personal que se promueve mediante el proceso creador en arteterapia corporal con enfoque de género, abre las puertas para que las mujeres logren ampliar sus niveles de conocimiento y participación, colaborando para disminuir las desigualdades aún existentes respecto a la vida pública y personal. De esta manera, en las participantes se fomenta el ir descubriendo las discriminaciones de género en sus imágenes (obras creadas), así como, la toma de conciencia sobre la importancia de continuar aspirando a una real igualdad de los derechos y el trato entre mujeres y hombres. 
Las producciones artísticas acompañan a las mujeres y las imágenes creadas adquieren un valor simbólico para ellas con lo cual van gradualmente potenciando su bienestar personal. Como señala Omenat (2006:139) "el grupo de arteterapia posibilita la creación de un espacio femenino, un espacio común donde explorar el mundo interno de cada mujer y establecer asociaciones entre lo individual, lo social y sus vinculaciones con la cultura de género".

La metodología basada en el trabajo sobre la misma experiencia de las participantes, en una retroalimentación constante de sí mismas y desde el grupo. Las estrategias metodológicas que son utilizadas corresponden a los métodos y técnicas del arteterapia, el trabajo corporal, sesiones experienciales, diálogo y reflexión.

Algunas de las temáticas que se desarrollaron en las sesiones fueron: Genealogía, somos herederas; Claves de la auto identidad; Una mirada biográfica a la autoestima; Cuerpo naciente; Imágenes corporales; Etnografia de la vida cotidiana; Habitar el cuerpo; De qué conversamos cuando hablamos de género; Entre dos orilla, Autorretrato en el lugar donde vives y Autorretrato donde te gustaría vivir; Nudos familiares y conyugales; Fronteras de mi cuerpo; Tiempo, espacios, horas; Mi tierra, mi cultura; entre otras.

El proceso creativo con los materiales gráficos -plásticos, las obras y su resignificación permiten percibir a las mujeres su belleza interior, descubrir la capacidad creativa en la resolución de conflictos o mejorar su crecimiento personal. A partir de las propuestas corporales se brinda la posibilidad de tomar conciencia del cuerpo, es una invitación a que la mujer aprenda a "habitarlo" y cuidarlo en cualquier momento de nuestra vida.

Además, se constituye como un espacio abierto, lúdico, dinámico e integrador, que a través del enfoque de género, tiene como fines promover la autoestima y empoderamiento de las mujeres y favorecer la creación de nuevos espacios de convivencia.

Se aportan también las intervenciones de la arteterapeuta, con reflexiones y claves desde la teoría feminista y enfoque de género, que enmarquen las vivencias personales en la construcción social y simbólica.

Se propone un método de evaluación continua que permita la resignificación personal en el caso que fuera necesario o la introducción de posibles mejoras. Después de la sesión se realizaba una observación de la información relevante para el proceso de cada participante, en aquellos casos que fue necesario se establecieron coordinaciones con el resto del equipo que atendía a la mujer, para poder integrarlas en sus atenciones y actividades en el CEPI, así como en su vida cotidiana. Se observa además la consecución de los objetivos para cada sesión, enmarcándolas en el tipo de participación, implicación y actitud hacia el grupo de casa participan. 


\section{Participantes y duración del grupo}

Las beneficiarias mayores de edad que deseen mejorar la relación con su cuerpo y el autoconocimiento, interesadas en participar en una actividad grupal destinada a mujeres, con un enfoque de género y por medio del arteterapia corporal.

Se accede directamente a petición de las mujeres interesadas o bien, a través de un informe de derivación de profesiones de la red de recursos públicos, o privados y del tejido asociativo comunitario que utiliza el CEPI Hispano Colombiano de Villaverde.

El grupo tuvo una duración de cuatro meses, durante los días martes de 16:00 a 18:00 hrs. y los días jueves de 10:30 a 12:30 hrs., las sesiones con una duración de dos horas y participaron 12 mujeres.

\section{Objetivos Generales}

- Promover el arteterapia corporal en grupos de mujeres.

- Impulsar el autoconocimiento por medio de la terapia corporal y en enfoque de género.

\section{Objetivos Específicos}

- Fortalecer el autoconocimiento y la relación con el cuerpo.

- Reflexionar sobre la identidad.

- Mejorar la autovaloración y confianza en sí misma.

- Familiarizarse con los materiales y técnicas arteterapéuticas.

- Estimular la expresión personal por medio del proceso de creativo.

- Reflexionar sobre las discriminaciones de género.

- Promover los derechos de la mujer.

\section{Encuadre y setting}

El diseño de la intervención se establece como un grupo cerrado, es decir, se inicia con un número fijo de participantes y después de la tercera sesión no se admiten nuevas integrantes. Las sesiones se desarrollan en un marco de trabajo rígido $^{7}$. El grupo es un lugar donde las mujeres encuentran confianza para poder expresar y crear, sin embargo, se debe tener en consideración desde el primer encuentro algunas normas hacia las creaciones personales, las compañeras, la puntualidad y un acuerdo de confidencialidad de los procesos y experiencias que se viven en el grupo ${ }^{8}$.

\footnotetext{
${ }^{7}$ Se inicia el proceso creativo con los temas y/o consignas que la arteterapeuta entrega al grupo.

${ }^{8}$ Cuando la mujer ingresa al grupo de solicita la autorización para fotografiar sus obras y para grabar en algunas sesiones durante sus procesos creativos, además se pide su consentimiento para el uso de sus imágenes o videos en congresos y publicaciones.
} 
Durante el proceso de creación cada mujer escoge libremente el material que desea utilizar: témperas, rotuladores, cartulinas, imágenes de revistas, plastilina, géneros, lanas, tijeras, material reciclados, etc. Al relacionarse con los materiales, cada una se encuentra consigo misma, con su capacidad de exploración y de creatividad.

Cuando se finaliza el proceso creativo viene un tiempo donde cada mujer toma distancia y observa su obra. Estas acciones facilitan una reflexión personal y ese es el momento donde se debe incentivar la observación entre la creadora y su obra y mediar para que dentro de lo posible la recepción del contenido, que lleva implícita la imagen, sea visualizada y adquiera significado para su autora. Se acompaña a las mujeres en sus descubrimientos, y también se impulsa la escucha interna respetando los ritmos personales y grupales, aceptando el silencio cuando se hace presente en el grupo.

Después de la observación de la obra, el grupo tiene la posibilidad de compartir lo experimentado. La idea es que las mujeres puedan intercambiar impresiones sobre el proceso creativo y las imágenes, así como, compartir sobre las experiencias vividas durante la sesión. Es en esta parte de la sesión, es cuando, a partir de las obras y los comentarios de las mujeres, se pueden hacer vinculaciones con temáticas relativas a las discriminaciones o estereotipos de género y los derechos de la mujer.

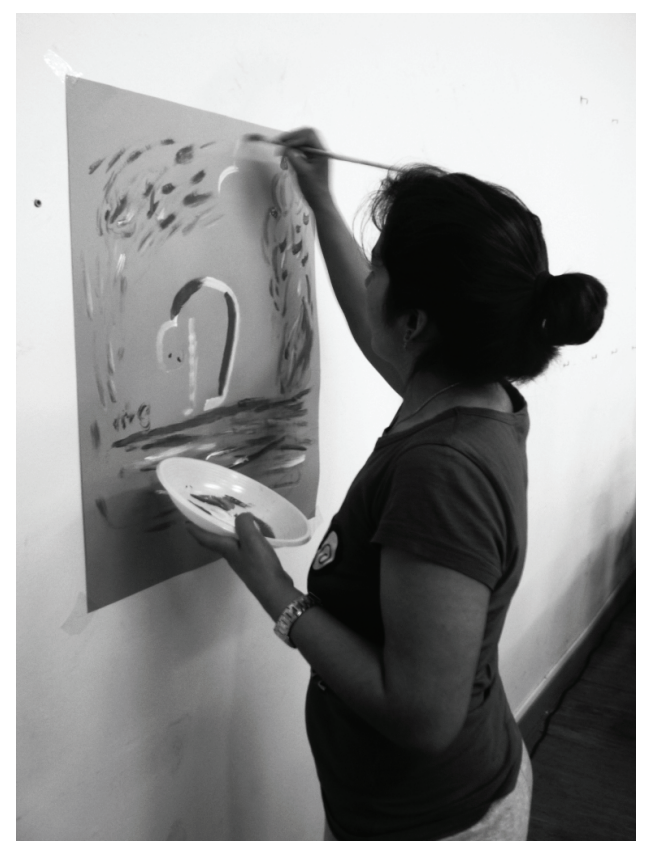

Fig. 2. Proceso creativo. 


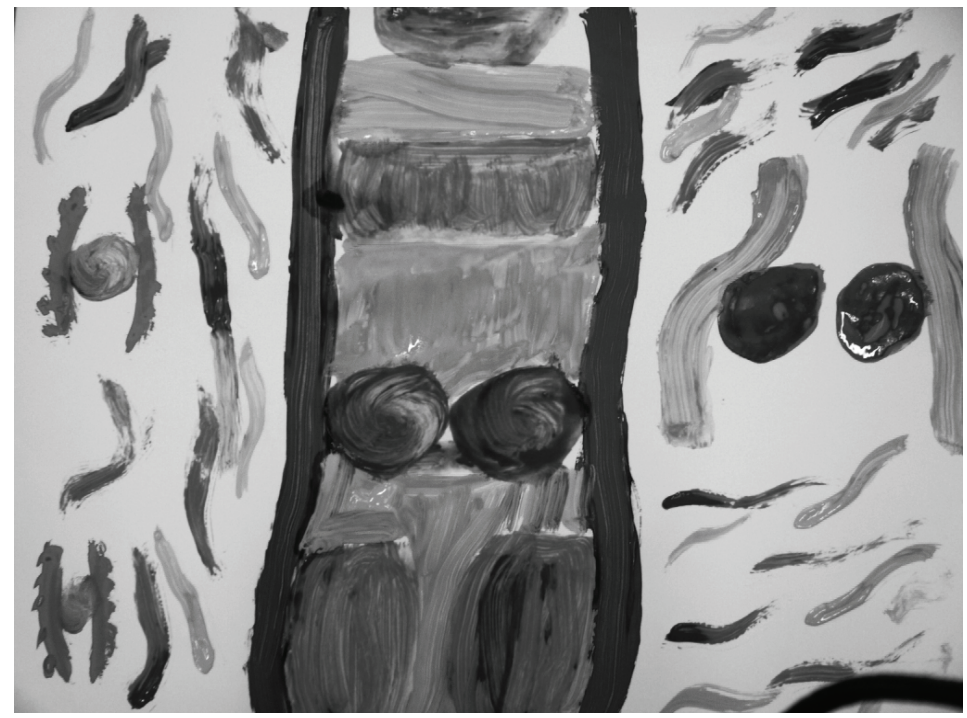

Fig. 3. Autora M: "Mis ovários atrapados".

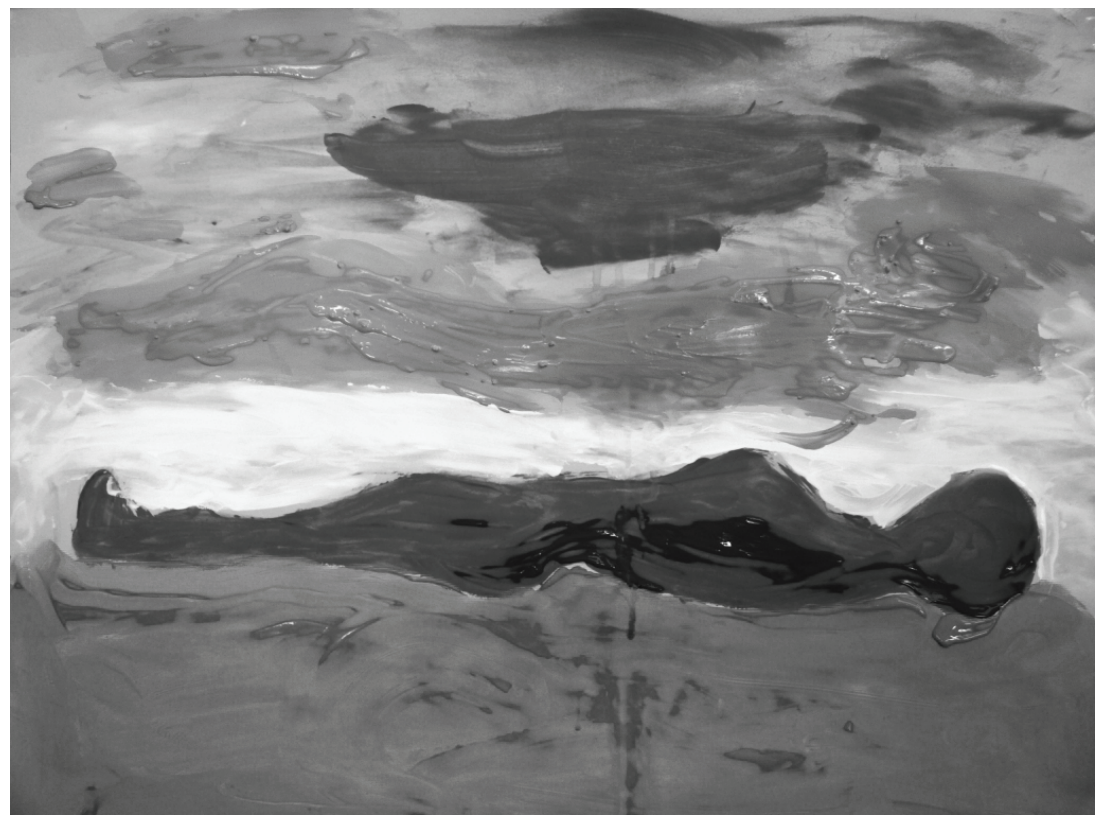

Fig. 4. Autora, P: "Mi cuerpo puede descansar" 


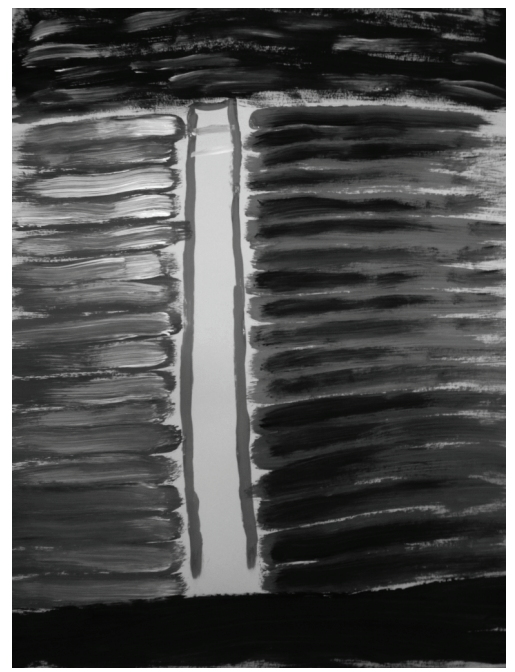

Como arteterapeuta, mi labor es proporcionar y contener el espacio donde las mujeres puedan reconocerse en su cuerpo, tomar conciencia de este y su importancia, mejorar la relación con su autoestima siempre desde el vínculo que existe entre la creadora y su obra. Además, empleando lenguajes artísticos combinados, he llegado a comprender que a la hora de acompañar un proceso creativo es clave ofrecer la mayor cantidad de materiales y técnicas artísticas dentro de la práctica profesional.

Fig. 5. Autora L: "No atiendo mis dolor"

\section{REFLEXIONES FINALES}

Durante el recorrido creativo, nos anima la voluntad de acceder a cierta comprensión de lo que va aconteciendo en el microcosmos de cada mujer, y la necesidad también de establecer vínculos con la migración, la discriminación de género, la exclusión social, la violencia y los derechos de las mujeres. En este sentido, el grupo de arteterapia corporal con enfoque de género permitió abordar el proceso de adaptarse a una nueva cultura, los malos tratos, los rechazos, las discriminaciones, la relación con su identidad, los miedos, las expectativas, las alegrías que se producen en la cotidianidad. Además las creaciones devolvieron a la mujer una conexión con su cuerpo y el género; logrando con el paso de las sesiones expresar, empatizar y recuperar en la medida de lo posible el autoconocimiento y la confianza en sí misma.

El objetivo central que se plantean para el grupo es impulsar el autoconocimiento por medio del arteterapia, la terapia corporal y el enfoque de género, podemos señalar que fue alcanzado por la mayoría de las participantes. Evidencia de ello fueron las evaluaciones continuas que se realizaban, así como, la retroalimentación recibida en las reuniones de evaluación de procesos que se realizaban con el equipo multiprofesional del proyecto.

Igualmente, las temáticas abordadas en las sesiones brindaron aportes trascendentales desde sus campos de acción; por un lado se rebelan contra aquellas prácticas que adormecen a las mujeres estableciéndolas en un presente continuo sin proyecto de futuro, y/o por otro lado, buscan favorecer el aquí y ahora, para cuestionar aquellas estructuras sociales que por su proximidad y cotidianeidad 
colocan a la mujer al borde de su propia extinción como persona. Conjuntamente, incorporar el enfoque de género permitió establecer el sustento necesario para construir un proyecto de arteterapia éticamente comprometida en sembrar en las mujeres la tendencia a desarrollar espacios de crecimiento personal, de toma de conciencia sobre el derecho a la autonomía y capacidad reproductiva, así como, favoreció el reconocimiento de espacios sociales sin exclusión.

Desde mi punto de vista como arteterapeuta e investigadora, resulta de gran complejidad y riesgo extraer conclusiones de experiencias arteterapéuticas con grupos de mujeres sin un seguimiento en el tiempo ${ }^{9}$, que permita observar los cambios de comportamiento en la actuación individual y relaciones con el entorno familiar y social. No obstante recoger las opiniones de las participantes por medio de la evaluación continua, la observación de sus actitudes y actuaciones durante sus procesos creativos, como sus obras, permite valorar como favorables los resultados en relación con los objetivos específicos del grupo.

Otra de las características del arteterapia es que las imágenes permanecen y podemos volver a ellas, evocar y sentir emociones diferentes a cuando se crearon. Esto para las mujeres que han participado, es la historia de un crecimiento. Compartir las emociones que emergen de las sesiones fue un modo eficaz para comunicarse con la arteterapeuta y con el grupo acerca de sus vivencias o inquietudes más profundas. Pero la comunicación verbal a raíz de las creaciones artísticas, no representa el objetivo último en arteterapia; el diálogo interno con las obras creadas, consciente e incluso el que no lo es, también puede representar para la mujer una ayuda considerable. Por otra parte, el proceso creativo propone una buena alternativa a la palabra, establece vías de comunicación que preparan un cauce para que sentimientos difíciles puedan emerger.

Aunque se reconoce la legitimidad del derecho de toda persona a salir de su país de origen, lo cierto es que la brecha creciente entre los instrumentos que definen y protegen los derechos humanos de personas migrantes y la realidad cotidiana obstaculiza la posibilidad de que la migración se convierta en una opción para las mujeres y contribuya a reducir las asimetrías en las relaciones de género (Martínez, R.P., 2009). Por lo tanto, es considerado como valioso por las mujeres poder hablar de experiencias que han sufrido de discriminación, exclusión social y violencia dentro del grupo de arteterapia, por medio de sus imágenes u objetos artísticos.

Dentro de las dificultades que podemos indicar encontradas en el desarrollo del grupo, fue el desafío que plantea incentivar el desbloqueo creativo propio de personas, que no se relacionan con una actividad artística y corporal desde que

\footnotetext{
${ }^{9}$ El proyecto tiene una duración de nueve meses y no se permite que para la siguiente convocatoria puedan participar las/os mismas/os integrantes del equipo multiprofesional. Esto implica que muchas de las intervenciones no se vuelven a repetir en el CEPI Hispano-Colombiano de Villaverde.
} 
eran niñas, y les parece totalmente ajena. Sin embargo, estás fueron desapareciendo prontamente, algunas mujeres ayudaban a sus compañeras en un clima cooperativo. Además, solamente cuatro mujeres debieron dejar el grupo, en su mayoría porque encontraban trabajo, lo anterior nos permite considerar que esta experiencia era valorada como positiva para su desarrollo personal por las mujeres participantes.

Para finalizar y como proyección, se reconoce la necesidad de continuar avanzando en el campo de las investigaciones y experiencias grupales de arteterapia con enfoque de género. Con el propósito de que estas experiencias promuevan el desarrollo de la profesión y se pueda consolidar como una disciplina de colaboración en las organizaciones que trabajan con mujeres migrantes. Además, estas intervenciones abordan las problemáticas de la mujer y trabajan por la igualdad de derechos y trato entre mujeres y hombres. Igualmente, el arteterapia es una herramienta para que las mujeres logren construir o reconstruir su identidad y pertenencia social, al quedar de manifiesto el efecto sanador y la capacidad expresiva del arte.

\section{REFERENCIAS BIBLIOGRÁFICAS}

BENERÍA, L. (1987). Género, diferencia y desigualdad, en Beltrán, E. y Maquieira, V. (Eds.) Feminismo debates teóricos contemporáneos, Madrid. Ciencias Sociales Alianza Editorial.

CORTÉS, P. (2005). Mujeres migrantes de América Latina y el Caribe: derechos humanos, mitos y duras realidades, serie Población y desarrollo, $\mathrm{N}^{\circ} 61$ (LC/L.2426-P), Santiago de Chile, Comisión Económica para América Latina y el Caribe (CEPAL). Publicación de las Naciones Unidas, $\mathrm{N}^{0}$ de venta: S.05.II.G.173.

DALLEY, T. (1987). El arte como terapia. Barcelona. Editorial Herder.

LAGARDE, M (2000). Claves Feministas para la Autoestima de las Mujeres.Madrid. Ediciones Cuadernos Inacabados, $\mathrm{N}^{\mathrm{o}} 39$.

MARTÍNEZ, J. (2006). Género y migración internacional en el espacio iberoamericano: algunas consideraciones en la búsqueda de buenas prácticas, documento presentado en el Encuentro iberoamericano sobre migración y desarrollo, Secretaría General Iberoamericana (SEGIB), Madrid, 18 y 19 de julio.

MARTÍNEZ, R.P. (2009). Extrañándonos de lo "normal". Reflexiones feministas para la intervención con mujeres drogodependientes". Madrid. Cuadernos Inacabados, horas y Horas, La Editorial. 
MARXEN, E. (2011). Diálogos entre arte y terapia. Barcelona: Gedisa.

OMENAT, M. (2006). Arteterapia con mujeres que han sufrido violencia de género: valor y uso del objeto artístico, en Coll Espinosa, F. (coord.). Arteterapia: Dinámicas entre creación y procesos terapéuticos. Murcia, España. Servicio de Publicaciones, Universidad de Murcia. pp. 225-264.

SALLÉ, M. (2009). Las mujeres, protagonista de la inmigración latinoamericana.. Madrid. Fundación Directa.

SAMUELS, M. Y ROCKWOOD, M. (2000). Creatividad Curativa. Buenos Aires. Vergara Editor.

ZONTINI, E. (2005). Migraciones, género y multiculturalismo. Una perspectiva de Europa Meridional, en Inmigración, género y espacios urbanos. Los retos de la diversidad, Mary Nash, Rosa Tello y Núria Benach (eds.). Barcelona. Ediciones Ballaterra. 